\title{
THE PAIRWISE COMPARISON VOTING METHOD AND THE ANALYTIC HIERARCHY PROCESS
}

\author{
Luis G. Vargas \\ Orrin Cooper \\ University of Pittsburgh
}

\begin{abstract}
Voting is the tool of democracy. Two very old voting schemes studied in voting theory are Borda's and Condorcet's methods. Using pairwise comparisons in the sense of the AHP we develop a method to decide which candidate is the winner of an election where voters rank the candidates in order of importance. We study the solution and provide conditions under which it is a Borda and a Condorcet alternative.
\end{abstract}

Keywords: voting, group decision making, pairwise comparison method 